\title{
Phytophagous hoverflies (Diptera: Syrphidae) as indicators of changing landscapes*
}

\author{
S. Popovi,6, M. Miličić2,3, I. Diti,5, O. Marko², D. Sommaggio4, Z. Markov \\ and A. Vujić ${ }^{1}$
}

IDepartment of Biology and Ecology, University of Novi Sad, Trg Dositeja Obradovića 2, 21000 Novi Sad, Serbia

${ }^{2}$ BioSense Institute - Research Institute for Information Technologies in Biosystems, University of Novi Sad,

Trg Dr Zorana Đinđića 1, 21000 Novi Sad, Serbia

${ }^{3}$ Finnish Museum of Natural History, Zoology Unit, University of Helsinki, Pohjoinen Rautatiekatu 13, 00100 Helsinki, Finland

${ }^{4}$ Department of Agricultural Sciences, University of Bologna, Viale G. Fanin 42, 40127 Bologna, Italy

${ }^{5}$ Department of Sustainable Crop Production, Università Cattolica del Sacro Cuore, 29100 Piacenza, Italy

${ }^{6}$ Corresponding author. Fax: (+381) 21450 620; E-mail: snezana.jovicic@dbe.uns.ac.rs

Keywords: Bioindicators, Connectivity, Cheilosia, Insects, Land cover change, Landscape structure, Merodon, Species richness.

\begin{abstract}
Spatial and temporal differences in landscape patterns are of considerable interest for understanding ecological processes. In this study, we assessed habitat quality by using the Syrph The Net database and data on decreasing species richness over a 25-year period for the two largest phytophagous hoverfly genera (Merodon and Cheilosia). Furthermore, within this time frame, we explored congruence between ecological responses (species richness and Biodiversity Maintenance Function for these two genera) and landscape structural changes through correlation analysis. Our results indicate that landscapes have experienced changes in aggregation, isolation/connectivity and landscape diversity, with these parameters being significantly correlated with Cheilosia species richness loss and habitat quality. We conclude that the genus Cheilosia is a good bioindicator that can highlight not only the current quality of an area but also temporal changes in landscape patterns.
\end{abstract}

Nomenclature: Meigen (1803) for genus Merodon and Meigen (1822) for genus Cheilosia.

Abbreviations: BDMF-biodiversity maintenance function; CONN-Connectance Index; CONTAG-Contagion Index; DIVLandscape Division Index; ENN-Euclidean Nearest-Neighbor Distance; FRAC-Fractal Dimension Index; GYR-Radius of Gyration; LPI-Large Patch Index; LSI-Landscape Shape Index; PRD-Patch Richness Density; SHDI-Shannon's Diversity Index; SHEI-Shannon's Evenness Index; StN-Syrph The Net database.

\section{Introduction}

Global biodiversity is constantly being eroded as a consequence of human-induced pressures (Pimm 1995). One such pressure is landscape change (Foley et al. 2005, Tscharntke et al. 2005). Besides biotic and abiotic parameters, human influence has been determined as one of the main factors shaping landscape patterns (Rackham 1998, Moser et al. 2002). Disturbance of those patterns influences multiple ecological processes, thereby affecting both ecosystem functions and species within ecosystems (With 1997). In order to alleviate the negative consequences of landscape disturbances and to preserve imperiled species and areas, varying conservation measures have to be applied. However, due to limited resources for conservation action, proper estimation of conservation priorities is needed (Faith 1992). Therefore, it is crucial to identify bioindicator taxa that can reflect broad-scale impacts and exhibit measurable responses to different changes in the environment. Although species level is the most often considered taxonomic resolution, genus-level indicators could have significant values. Due to the specific larval food type of phytophagous genera, one can assume that the whole genera could be sensitive to changes in the environment and would have timely and measurable responses to these changes.

Landscape structure is a key element of our understanding of species diversity (Walz 2011) and it has been proven to significantly influence insect communities (Didham et al. 1996). Different landscape features (such as isolation of habitat fragments, patch area, patch quality, ratio of habitat edge to interior, etc.) affect insect richness and abundance in space. Thus, it is clear that insects can be used to assess changes in landscapes across time (Hunter 2002).

* The Student Conference on Conservation Science (SCCS) is organized each year in several locations, Tihany at the Lake Balaton in Hungary being one of them. Since 2016, Community Ecology offers a prize at SCCS Tihany for the best presentation in the field of community ecology. An independent jury awards the prize that is an invitation to submit a manuscript to the journal. This is the paper of the SCCS Tihany'2017 Awardee, Snezana Popov. 
Table 1. Research study sites: GPS coordinates and summary of landscape characteristics.

\begin{tabular}{|c|c|c|c|}
\hline Sites & Coordinates & Landscape matrix & Type of Landscape \\
\hline 1 & $\mathrm{~N}_{4}{ }^{\circ} 0^{\prime} 55.48 \mathrm{E} 21^{\circ} 52^{\prime} 54.77$ & Broadleaf forest (Quercus \& Fagus) & Low mountain \\
\hline 2 & $\mathrm{~N}^{\prime} 4^{\circ} 0^{\prime} 47.12 \mathrm{E} 21^{\circ} 55^{\prime} 32.81$ & Broadleaf forest (Quercus \& Fagus) & Low mountain \\
\hline 3 & $\mathrm{~N} 44^{\circ} 1^{\prime} 43.59 \mathrm{E} 21^{\circ} 57^{\prime} 29.33$ & Broadleaf forest (Quercus) & Low mountain \\
\hline 4 & $\mathrm{~N} 44^{\circ} 1^{\prime} 1.22 \mathrm{E} 21^{\circ} 57^{\prime} 35.77$ & Broadleaf forest (Quercus) & Low mountain \\
\hline 5 & $\mathrm{~N} 45^{\circ} 10^{\prime} 44.22 \mathrm{E} 19^{\circ} 51^{\prime} 55.54$ & Broadleaf forest (Quercus) & Low mountain \\
\hline 6 & $\mathrm{~N} 43^{\circ} 16^{\prime} 39.11 \mathrm{E} 20^{\circ} 46^{\prime} 32.24$ & Conifer forest (Picea) & High mountain \\
\hline 7 & $\mathrm{~N}^{\prime} 3^{\circ} 21^{\prime} 15.38 \mathrm{E} 20^{\circ} 44^{\prime} 40.33$ & Conifer forest (Picea) \& Broadleaf forest (Fagus) & High mountain \\
\hline 8 & $\mathrm{~N} 43^{\circ} 19^{\prime} 22.80 \mathrm{E} 20^{\circ} 44^{\prime} 57.84$ & Conifer forest (Picea) & High mountain \\
\hline 9 & $\mathrm{~N} 43^{\circ} 19^{\prime} 0.64 \mathrm{E} 22^{\circ} 48^{\prime} 5.98$ & Conifer forest (Picea) & High mountain \\
\hline 10 & $\mathrm{~N} 43^{\circ} 14^{\prime} 1.79^{\prime \prime} \mathrm{E} 22^{\circ} 46^{\prime} 53.35$ & Broadleaf forest (Fagus) \& Conifer forest (Picea) & High mountain \\
\hline
\end{tabular}

In our study, we focused on the Syrphidae; a Dipteran insect family. Around 6000 hoverfly species have been described worldwide to date (Pape et al. 2011). They mainly feed on pollen and nectar and are considered the second-most significant group of pollinators after bees (Petanidou et al. 2011). In order to ensure the persistence of these species in Serbia, keystone habitats (PHA-Prime Hoverfly Area) were assigned (Vujic at al. 2016), while Miličić et al. (2017) conducted area prioritization for Southeast Europe based on distribution and vulnerability of hoverflies. Their role as a bioindicator has been particularly recognized through the development of the Syrph The Net ( $\mathrm{StN})$ database, representing an expert system for analyzing and evaluating hoverfly communities. The "biodiversity maintenance function" (BDMF) can be used as an estimate of site quality and is calculated by comparing the expected biodiversity within a habitat type on a site with its observed biodiversity. BDMF is the main output of StN and represents the ratio between the observed number of species to the total number predicted by StN (Speight 2008). Lists of predicted species can be generated by considering regional lists of species and matching the habitat preferences of each species to the habitats available at a given site (Speight and Castella 2001). Numerous studies have successfully used this database for habitat evaluations, confirming the potential of hoverflies as bioindicators (Speight and Castella 2001, Sarthou et al. 2005, Velli et al. 2010, Sommaggio and Burgio 2014). However, unlike the previous studies assessing the bioindicator role of syrphids based only on present information, in this study we examine the changes over time both in landscape structure and in species richness. Specifically, we targeted the two largest European hoverfly genera, Cheilosia Meigen, 1822 and Merodon Meigen, 1803. These genera have been the focus of numerous field surveys in Serbia over the last 35 years, so their distributions and habitat preferences are well known (Vujić, pers. comm.). Additionally, species of these two genera can be considered specialists, having larvae that are phytophagous and often linked to a specific plant genus or species (Rotheray and Gilbert 2011). It is widely acknowledged that specialized species are more sensitive to environmental change than generalists (O'Grady et al. 2004,
Isaac et al. 2009), implying that these species will exhibit rapid and measurable responses to landscape changes.

Jovičić et al. (2017) showed that landscape structure and land use patterns affect both Cheilosia and Merodon species. Here, we investigate (i) the effects of landscape structural change on Merodon and Cheilosia species richness at both spatial and temporal scales, and (ii) the bioindicator potential of these species using BDMF calculated for data spanning 25 years. To fulfill our objectives, we assess whether there have been shifts in the communities of these two hoverfly genera and, if so, we test whether these shifts are associated with changes in landscape structure.

\section{Material and methods}

\section{Data on hoverfly species richness}

Hoverfly species distributions throughout Serbia have been investigated regularly over the last 35 years. The Faculty of Science of the University of Novi Sad, Serbia, hosts an internal database comprising a large amount of geo-referenced data on hoverfly species presence. For the purposes of this study, we selected 10 sites from the database (Table 1), which were recently surveyed by the authors over a 4-year period (2011-2014). Sites were chosen by experts based on knowledge about the ecological preferences of species from the genera Merodon and Cheilosia. A detailed description of the sites and all of their macrohabitats can be found in Jovičić et al. (2017).

Specimens were counted during peak flight periods, from April to the end of August, using entomological netting. The StN database consists of information on adult hoverfly species collected using Malaise traps. However, a major limitation of using Malaise traps for sampling hoverflies is that they are often vandalized or damaged by grazing animals (Speight et al. 2000). We chose to use entomological netting as a sampling method for our study instead of Malaise traps for two reasons. First, for a large number of our sites, we could not adequately protect Malaise traps. Secondly, data in our internal database for the period 1990-2010 were collected using 
Table 2. Landscape metrics used to quantify landscape structure and to assess landscape structural change; calculated in Fragstat.

\begin{tabular}{|c|c|c|}
\hline GroupType & Landscape metrics & Description \\
\hline Area \& edge & Radius of Gyration (GYR)* & $\begin{array}{l}\text { Measure of patch extent; it describes how far across the landscape a } \\
\text { patch extends its reach. }\end{array}$ \\
\hline \multirow[t]{2}{*}{ Shape } & Large Patch Index (LPI)* & $\begin{array}{l}\text { Index of dominance that equals the percentage of landscape } \\
\text { comprised by the largest patch }\end{array}$ \\
\hline & Fractal Dimension Index (FRAC) & Describes the complexity of a patch's perimeter. \\
\hline \multirow[t]{2}{*}{ Aggregation } & Contagion Index (CONTAG)* & $\begin{array}{l}\text { Index measuring the degree of clumping of attributes on raster } \\
\text { maps. }\end{array}$ \\
\hline & Landscape Shape Index (LSI)* & $\begin{array}{l}\text { Describes the regularity of landscape patches in the considered } \\
\text { landscape }\end{array}$ \\
\hline Subdivision & Landscape Division Index (DIV)* & Describes how much the landscape is subdivided into patches. \\
\hline \multirow{3}{*}{ Diversity } & Patch Richness Density (PRD)* & Measure of landscape diversity. \\
\hline & Shannon's Evenness Index (SHEI)* & $\begin{array}{l}\text { Describes the proportion of the landscape occupied by a certain } \\
\text { class. }\end{array}$ \\
\hline & Shannon's Diversity Index (SHDI) & $\begin{array}{l}\text { Describes how many patches of the same type are dispersed in the } \\
\text { landscape. }\end{array}$ \\
\hline \multirow[t]{2}{*}{ Isolation } & Euclidean Nearest-Neighbor Distance (ENN)* & Quantifies patch isolation. \\
\hline & Connectance Index (CONN) & Describes connectivity between patches of the same class. \\
\hline
\end{tabular}

entomological nets. Thus, in order to compare our findings among years, we decided to use the same sampling method. Additionally, entomological netting is considered to be more efficient than Malaise traps (Marcos-García et al. 2012).

\section{Data on landscape structural change}

Landscape structural change was evaluated using GIS tools and relevant ecological software. We based our analysis on CORINE land cover maps in vector format from 1990, 2006 and 2012, using the ArcGIS software package (ArcGIS10, ESRI). We established circular zones with radii of $2 \mathrm{~km}$ and $5 \mathrm{~km}$ around each site. The Fragstat 4.2 software (McGarigal et al. 2002) was used to calculate landscape metrics based on prepared maps that had previously been converted into ERDAS raster format $(15 \mathrm{~m} / \mathrm{pixel})$. In total, we selected 11 landscape metrics aimed at describing landscape structure and change over 25 years, three of which were based on previous research on the influence of landscape structure on Merodon and Cheilosia communities (Jovičić et al. 2017) and further eight metrics were added (Table 2; indicated with asterisks) because we assumed that over longer time periods they would influence species richness of the two investigated genera.

\section{Data analysis}

\section{Syrph The Net analysis}

A detailed description of the process of calculating BDMF can be found in Speight et al. (2000). We calculated BDMF for each of the 10 analyzed sites. We adopted a threshold of $50 \%$ to indicate sites of good conservation status. Thus, if less than $50 \%$ of expected species were recorded for a given site (BDMF $<50 \%$ ), it may be considered degraded (Speight et al. 2000), whereas BDMF $>50 \%$ indicates sites with good habitat quality.

\section{Correlations among ecological and landscape variables}

Our dataset was comprised of ecological (Merodon and Cheilosia species richness and BDMF) and landscape variables [Radius of Gyration (GYR), Large Patch Index (LPI), Fractal Dimension Index (FRAC), Contagion Index (CONTAG), Landscape Shape Index (LSI), Landscape Division Index (DIV), Patch Richness Density (PRD), Shannon's Evenness Index (SHEI), Shannon's Diversity Index (SHDI), Euclidean Nearest-Neighbor Distance (ENN), Connectance Index (CONN)]. We had two data points for the ecological parameters, i.e., for periods 1990-2006 and 20062014, and three data points for landscape parameters, i.e., for individual years 1990, 2006 and 2014. In order to bring two sets of parameters to the common time-frame, we calculated the landscape parameters for the periods for which we had the measurements of ecological parameters (1990-2006 and 2006-2014). We did this by calculating the average value for each period:

1) $p(1990+p 2006) / 2$;

2) $p(2006+p 2012) / 2$

where $p$ stands for parameter value. 
To test whether there was a relationship between changing landscape parameters over the 25-year time-frame and the three ecological parameters, we calculated the correlation between the corresponding columns from the first and the second matrix. Kolmogorov-Smirnov test showed that there was a large and significant distance between the normal distribution and empirical distribution function of the three ecological parameters (all $\mathrm{p}<.001)$. This means that we can assume with a high certainty that the samples are not normally distributed. Hence, the use of Pearson correlation is not appropriate and Spearman's rank correlation was used instead. The resulting correlations, calculated in MATLAB, are given in Table 3 , where all statistically significant results are indicated by asterisks.

\section{Results}

Landscape structural change over 25 years

We found interesting trends regarding landscape structural change for the first time period (1990-2006). Within the 2 $\mathrm{km}$ buffer, an increase in the LPI and LSI indices indicated a simplification of landscape patches (Appendix 1). The larger and more symmetric patches, together with the higher complexity of patch perimeter shapes (decreased FRAC index), confirm that over this period patches became more regular in shape. Moreover, within the $5 \mathrm{~km}$ buffer areas, the CONTAG and CONN metrics exhibited negative trends, signifying that similar patches became less connected. The different CONN values between the 2 and $5 \mathrm{~km}$ buffers indicate different landscape patterns at these two scales; the $2 \mathrm{~km}$ buffers manifest higher connectivity (a mean of approximately $70 \%$ ), whereas connectivity was approximately $40 \%$ for the $5 \mathrm{~km}$ buffers. Our data also revealed an increase in the LSI index for 1990-2006, with an average value of $+6.4 \%$ indicating an increase in the regularity of landscape patterning in this period.
However, this trend was reversed for the following years (an average value of $-7.5 \%$ for 2006-2014), with the lowest value at site 5 where urbanization is more pronounced. We found the same trend for the DIV index. One of the most widely used landscape metrics in landscape ecology, Shannon's Diversity Index, indicated a decrease in dispersion of patches across the investigated landscapes.

\section{Analysis of changes in species richness and site quality (BDMF) over 25 years}

In percentage terms, the greatest decrease in species richness in both genera for the period 1990-2014 was observed at sites 1, 2, and 5 (Fig. 1, Electronic Appendix A2). The greatest decrease in Merodon species richness was recorded at site 8, whereas the genus Cheilosia suffered the greatest decrease in species richness at site 2 . The only site where no change in species richness was observed was site 4 .

Mean BDMF for the first period (BDMF1; 1990-2006) was $50.7 \%$; the highest mean value was observed for site 7 (77.8\%), whereas the lowest mean value was found for site 9 (29\%). All BDMF1 and BDMF2 values (2006-2012) are presented in Figure 2. According to the BDMF classification, currently six sites can be considered as degraded habitats, with BDMF values $<50 \%$ (sites 1, 2, 4, 5, 9 and 10), whereas three sites can be classed as "good quality" habitats (3, 6 and 8) with BDMF values ranging between 50 and $74 \%$. Only one site (7) presented a value $>75 \%$, indicating the highest habitat quality.

\section{Correlations among ecological and landscape variables}

Our results showed differences in correlation patterns between changes in landscape variables and species richness of the two genera (Tables 3 and 4). Although there was no correlation between Merodon species richness and landscape

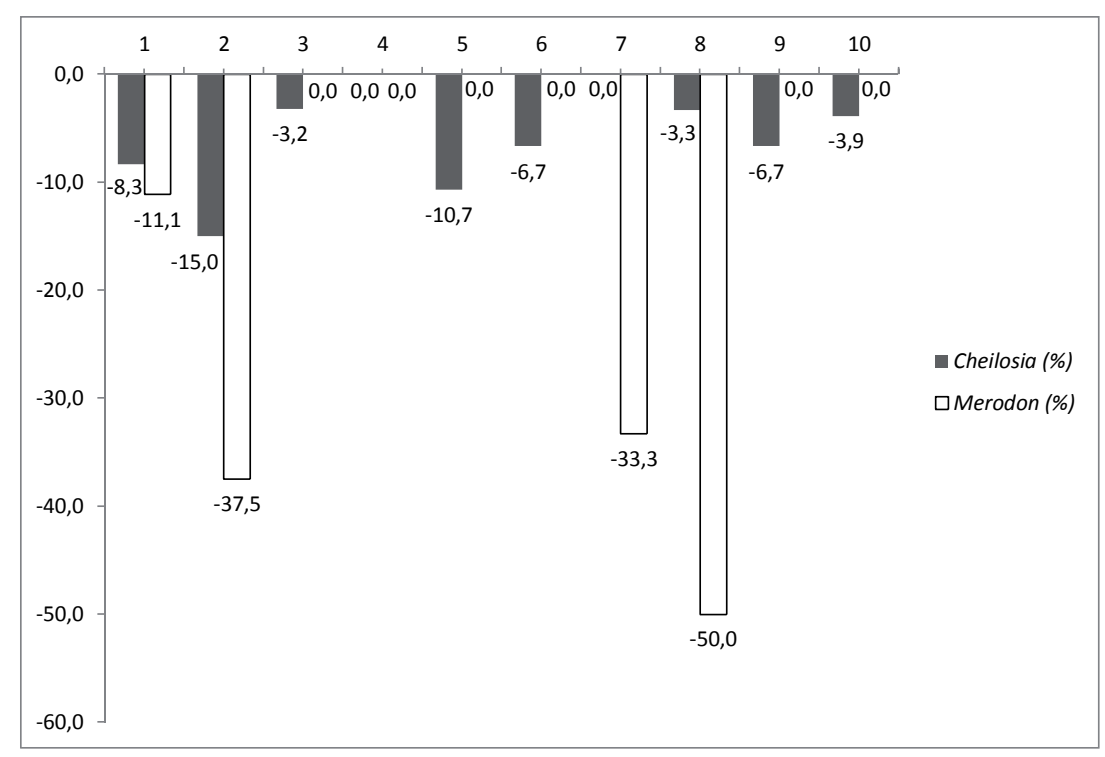

Figure 1. Observed change in percentage for Merodon and Cheilosia species richness based on the ten study sites, between 19902014. 
Table 3. Correlations among ecological (Cheilosia and Merodon species richness and BDMF) and landscape variables [Radius of Gyration (GYR), Large Patch Index (LPI), Fractal Dimension Index (FRAC), Contagion Index (CONTAG), Landscape Shape Index (LSI), Landscape Division Index (DIV), Patch Richness Density (PRD), Shannon's Evenness Index (SHEI), Shannon's Diversity Index (SHDI), Euclidean Nearest-Neighbor Distance (ENN), Connectance Index (CONN)].

\begin{tabular}{|c|c|c|c|c|c|c|c|c|c|c|c|}
\hline & LPI & LSI & GYR & FRAC & ENN & CONTAG & CONN & DIV & PRD & SHI & SHEI \\
\hline Cheilosia & -0.470 & $0.683^{*}$ & 0.128 & 0.329 & 0.195 & 0.067 & $0.689^{*}$ & 0.433 & -0.604 & 0.098 & -0.018 \\
\hline Merodon & -0.464 & 0.212 & 0.369 & 0.505 & -0.055 & 0.225 & 0.615 & 0.553 & -0.137 & 0.355 & -0.225 \\
\hline BDMF & -0.390 & 0.232 & 0.591 & 0.567 & 0.183 & 0.067 & $0.726^{*}$ & 0.396 & $-0.707^{*}$ & 0.159 & 0.006 \\
\hline
\end{tabular}

Table 4. P-values of correlations among ecological (Cheilosia and Merodon species richness and BDMF) and landscape variables [Radius of Gyration (GYR), Large Patch Index (LPI), Fractal Dimension Index (FRAC), Contagion Index (CONTAG), Landscape Shape Index (LSI), Landscape Division Index (DIV), Patch Richness Density (PRD), Shannon's Evenness Index (SHEI), Shannon's Diversity Index (SHDI), Euclidean Nearest-Neighbor Distance (ENN), Connectance Index (CONN)].

\begin{tabular}{crcccccccccc}
\hline & LPI & LSI & GYR & FRAC & ENN & CONTAG & CONN & DIV & PRD & SHI & SHEI \\
\hline Cheilosia & 0.171 & 0.030 & 0.724 & 0.353 & 0.589 & 0.854 & 0.028 & 0.211 & 0.065 & 0.789 & 0.960 \\
& & & & & & & & & & & \\
Merodon & 0.176 & 0.557 & 0.294 & 0.136 & 0.881 & 0.531 & 0.059 & 0.097 & 0.707 & 0.314 & 0.531 \\
& & & & & & & & & & & \\
BDMF & 0.265 & 0.519 & 0.072 & 0.087 & 0.613 & 0.854 & 0.018 & 0.257 & 0.022 & 0.662 & 0.987 \\
& & & & & & & & & & & \\
\hline
\end{tabular}

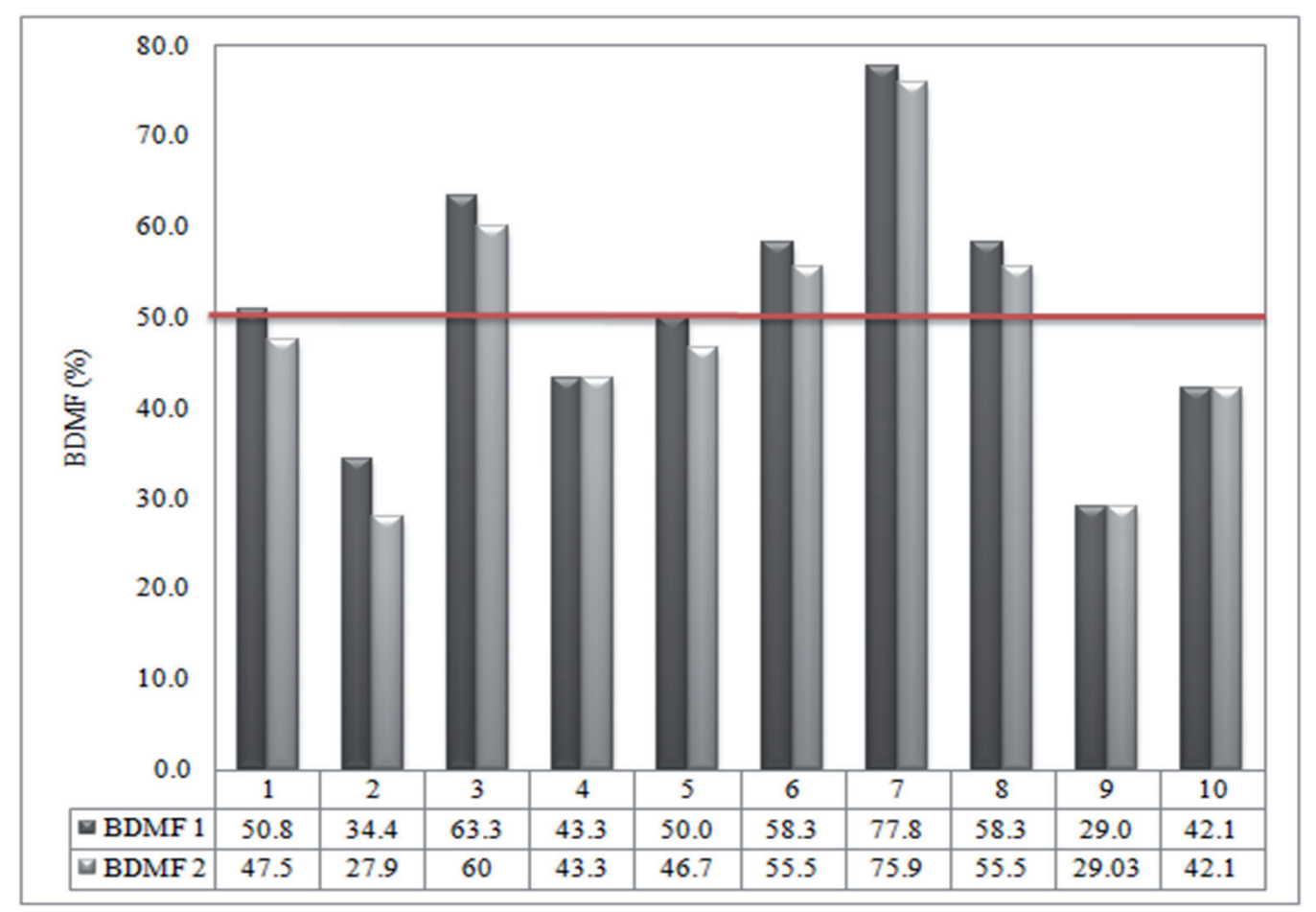

Figure 2. Comparison of BDMF values for 10 study sites (1-10) for two time periods: BDMF1 (1990-2006) and BDMF2 (2006-2014). The thick horizontal line represents the threshold $(50 \%)$ for good quality habitats. BDMF = biodiversity maintenance function; the ratio between observed and predicted species. 
changes, Cheilosia species richness proved to be significantly positively correlated to LSI $(r=0.683, p<0.05)$, and CONN $(\mathrm{r}=0.689, \mathrm{p}<0.05)$. Additionally, BDMF was strongly and positively correlated to $\mathrm{CONN}(\mathrm{r}=0.726, \mathrm{p}<0.05)$, and negatively correlated to $\operatorname{PRD}(\mathrm{r}=-0.707, \mathrm{p}<0.05)$. It is also worth noting that spatial scale influenced the response of all investigated ecological parameters since statistical significance was only observed at the smaller spatial scale $(2 \mathrm{~km})$, while on $5 \mathrm{~km}$ scale parameters did not show statistically significant correlations.

\section{Discussion}

Influence of landscape variables on hoverflies over 25 years

Our analysis revealed quantitative changes in landscape structure over a 25 -year period, as well as significant hoverfly species richness loss during this time frame. Landscape changes can be driven by quite distinct sets of factors (Koomen et al. 2007). SHDI, one of the most widely-used metrics in landscape pattern analysis, characterizes landscape composition in terms of diversity at the landscape level. Values of this metric for the 2 and $5 \mathrm{~km}$ buffer zones, together with CONTAG values, revealed an overall decrease in dispersion of the investigated sites, probably due to reduced fragmentation. Two components contribute to calculations of SHDI: richness (defined as the number of different patch types) and evenness in the distribution of areas among patch types (Eiden et al. 2017). Previous studies have documented the potential of SHDI to explain contemporary hoverfly species richness (Földesi et al. 2015, Jovičić et al. 2017). However, the results of the present study showed no significant relationship between this landscape variable and species richness, nor between SHDI and BDMF over the 25-year study time frame. Heterogeneous land cover types can increase hoverfly species richness (Büchs 2003), but if increased landscape heterogeneity involves an increase in the number of habitats that are not suitable for hoverflies, heterogeneity in itself will not support hoverfly macro-habitat requirements. Another measure of landscape diversity used in our analysis was PRD. The negative correlation between PRD and BDMF confirms that an understanding of biology and ecology of bioindicators is of utmost importance in landscape analyses, and that the selection of landscape parameters and their interpretation almost always depends on species preferences. The influence of landscape diversity on hoverfly species richness has rarely been studied through the lens of historical ecology, so additional research is needed to better understand its effects.

LSI is a landscape shape index, values of which increase with increasing shape irregularity and disaggregated areas within the landscape. This index was positively related to Cheilosia species richness, but did not significantly influence the response of the genus Merodon nor BDMF over the 25year period.

Our correlation analysis revealed a strong relationship between BDMF and the CONN parameter during the time frame we considered. The strong positive correlation most likely indicates that loss of connectivity in the landscape is the main cause of habitat quality degradation, ultimately leading to loss of species. However, this outcome primarily relates to the genus Cheilosia, since a statistically significant positive correlation was found between Cheilosia species richness and CONN, but not between Merodon species richness and CONN. The effects of landscape structure on different insect pollinator groups vary according to species mobility and foraging behavior (Steffan - Dewenter et al. 2002), clearly highlighting the response as being taxon-specific (Jovičić et al. 2017). Given the fact that connectivity is a key concept relating to the ecological effects of environmental change, future research should include more detailed methods for quantifying the network connectivity of landscapes mosaics, i.e., the Harary index (Ricotta et al. 2006).

\section{Bioindicator role of hoverflies}

Due to its inherent complexity, biodiversity cannot be easily measured so appropriate descriptors (surrogates, indicators) need to be selected (Schindler et al. 2012). Here, we tested the bioindicator role of two phytophagous hoverfly genera by utilizing the StN database and BDMF values to assess habitat quality. A decrease of $9.25 \%$ for the mean value of BDMF across all sites over the last 25 years indicates decreased site quality. We found that sites belonging to both the "degraded" and "good quality" categories exhibited quality degradation. For example, two sites (1 and 5) were downgraded from being good quality to degraded sites. These sites have been affected by agricultural activities, which could contribute to habitat disturbance and, consequently, impact species richness (loss). In particular, expansion of agricultural fields at the expense of forests has had a negative impact on species of Cheilosia. Moreover, site 5 has undergone urbanization, which can strongly influence its capacity to support hoverfly assemblages. Our StN analysis of these two taxonomic groups provides insights into the relationship between the species richness of these two genera and landscape structural change. We conclude that due to its sensitivity, the genus Cheilosia could be used as an effective indicator of landscape change over long time periods. Moreover, a recent study by Radenković et al. (2017) confirms a higher sensitivity of the genus Cheilosia to environmental changes; the genus Cheilosia would be more negatively affected by future climate change than Merodon on the Balkan Peninsula. Meyer et al. (2009) found that land-use change differentially affects hoverfly species depending on their specific larval feeding habits as well as their microhabitats. Modified ecosystems can support better Merodon species due to the availability of their larval host plants (Jovičić et al. 2017). On the contrary, Cheilosia species are sensitive to environmental disturbance, especially of forests. Undisturbed forest habitats enable them to have continuity of the microclimate they prefer. If the microclimate changes, species may become endangered.

It is important to underline that hoverflies are a diverse taxon, constituted by genera with different ecological requirements (Sommaggio 1999, Rotheray and Gilbert 2011). 
Extending this type of analysis to all genera in the family Syrphidae could be useful, especially if taxa with trophic characteristics other than phytophagy are considered. The use of functional traits rather than numbers of species seems to be more useful for assessing the conservation of habitats (Moretti et al. 2009, Vandewalle et al. 2010). Our research confirms StN as a useful tool for detecting differences between sites, including capturing the effect of changes in landscape complexity over a long period of time.

Our study confirms that spatio-temporal patterns of landscape change need to be considered when planning for conservation management activities (Senapathi et al. 2015). We conclude that shifts in hoverfly assemblages occur in those landscapes that have experienced the greatest change in various landscape characteristics, such as aggregation, isolation/ connectivity and diversity. Consequently, we have confirmed the bioindicator role of hoverflies through the patterns our data have revealed. Thus, we recommend that the landscape metrics that best describe these patterns, together with the $\mathrm{StN}$ database, be used as management tools in conservation management strategies to ensure the sustainable conservation of hoverfly diversity.

Acknowledgements: We kindly thank J. O'Brien for English proofreading and Dr G. Burgio for contributions while developing the original idea of this study. This work was supported by the Ministry of Education, Science and Technological Development, Republic of Serbia, under Grant No. 173002 and Grant No. 43002, the Provincial Secretariat for Science and Technological Development under Grant No. 114-4572173/2011-01, and H2020 project ANTARES under Grant No. 664387.

\section{References}

Büchs, W. 2003. Biodiversity and agri-environmental indicators-general scopes and skills with special reference to the habitat level. Agric. Ecosyst. Environ. 98:35-78.

Didham, R.K., J. Ghazoul, N.E. Stork and A.J. Davis. 1996. Insects in fragmented forests: a functional approach. Trends Ecol. Evol. 11:255-260.

Eiden, G., M. Kayadjanian and C. Vidal. 2017. Capturing landscape structures: Tools. (retrieved September 10, 2017 from http:// ec.europa.eu/agriculture/publi/landscape/ch1.htm).

Faith, D.P. 1992. Conservation evaluation and phylogenetic diversity Biol. Conserv. 61:1-10.

Földesi, R., A. Kovács-Hostyánszki, Á. Kőrösi, L. Somay, Z. Elek, V. Markó, M. Sárospataki, R. Bakos, Á. Varga, K. Nyisztor and A. Báldi. 2015. Relationships between wild bees, hoverflies and pollination success in apple orchards with different landscape contexts. Agric. For. Entomol. 18:68-75.

Foley, J.A., R. DeFries, G.P. Asner, C. Barford, G. Bonan, S.R Carpenter, F.S. Chapin, M.T. Coe, G.C. Daily, H.K. Gibbs, J.H. Helkowski, T. Holloway, E.A. Howard, C.J. Kucharik, C. Monfreda, J.A. Patz, I.C. Prentice, N. Ramankutty and P.K. Snyder. 2005. Global consequences of land use. Science 309:570-574.

Hunter, M.D. 2002. Landscape structure, habitat fragmentation, and the ecology of insects. Agric. For. Entomol. 4:159-166.
Isaac, J.L., J. Vanderwal, C.N. Johnson and S.E. Williams. 2009. Resistance and resilience: quantifying relative extinction risk in a diverse assemblage of Australian tropical rainforest vertebrates. Divers. Distrib. 15:280-288.

Jovičić, S., G. Burgio, I. Diti, D. Krašić, Z. Markov, S. Radenković and A. Vujić. 2017. Influence of landscape structure and land use on Merodon and Cheilosia (Diptera: Syrphidae): contrasting responses of two genera. J. Insect Conserv. 21:53-64.

Koomen, E., J. Stillwell, A. Bakema and H.J. Scholten. 2007. Modelling Land-Use Change. Springer Netherlands. CITY

Marcos-García, M.A., A. Garcia-Lopez, M.A. Zumbado and G.E. Rotheray. 2012. Sampling methods for assessing syrphid biodiversity (Diptera: Syrphidae) in tropical forests. Environ. Entomol. 41:1544-52.

McGarigal, K., S.A. Cushman, M.C. Neel and E. Ene. 2002. FRAGSTATS: Spatial Pattern Analysis Program for Categorical Maps. Computer software program produced by the authors at the University of Massachusetts, Amherst. Available from: http:// www.umass.edu/ landeco/research /fragstats/ fragstats.html

Meigen, J.W. 1803. Versuch einer neuen Gattungs-Eintheilung der europaischen zweiflugligen Insekten. Mag. Insektenkd. 2:259281

Meigen, J.W. 1822. Systematische Beschreibung der bekannten europaischen zweiflugeligen Insekten. Dritter Theil. SchulzWundermann, Hamm. $\mathrm{x}+416 \mathrm{pp}$.

Meyer, B., Jauker, F. and Steffan-Dewenter, I. 2009. Contrasting resource-dependent responses of hoverfly richness and density to landscape structure. Basic and Appl. Ecol. 10, 178-186.

Miličić, M., A. Vujić, T. Jurca and P. Cardoso. 2017. Designating conservation priorities for Southeast European hoverflies (Diptera: Syrphidae) based on species distribution models and species vulnerability. Insect Conserv. Divers. 10, 354-366.

Moretti, M., F. de Bello, S.P.M. Roberts, S.G. Potts. 2009 Taxonomical vs. functional responses of bee communities to fire in two contrasting climatic regions. J. Anim. Ecol. 78:98-108.

Moser, D., H.G. Zechmeister, C. Plutzar, N. Sauberer, T. Wrbka and G. Grabherr. 2002. Landscape patch shape complexity as an effective measure for plant species richness in rural landscapes. Landsc. Ecol. 17:657-669.

O’Grady, J. J., D.H. Reed, B.W. Brook and R. Frankham. 2004. What are the best correlates of predicted extinction risk? Biol. Conserv. 118:513-520.

Pape, T., V. Blagoderov and M.B. Mostovski. 2011. Order Diptera Linnaeus, 1758. In: Z.Q. Zhang (ed.), Animal Biodiversity: An Outline of Higher-level Classification and Survey of Taxonomic Richness. Magnolia Press, Auckland, New Zealand. pp. 222-229.

Petanidou, T., A. Vujić and W.N. Ellis. 2011. Hoverfly diversity (Diptera: Syrphidae) in a Mediterranean scrub community near Athens, Greece. Ann. Soc. Entomol. Fr. 47:168-175.

Pimm, S.L., G.J. Russell, J.L. Gittleman and T.M. Brooks. 1995. The future of biodiversity. Science 269:347-350.

Rackham, O. 1998. Savanna in Europe. In: K.J. Kirby and C. Watkins (eds.), The Ecological History of European Forests. Cambridge University Press, Cambridge, UK. pp. 1-24.

Radenković, S., O. Schweiger, D. Milić, A. Harpke and A. Vujić 2017. Living on the edge: Forecasting the trends in abundance and distribution of the largest hoverfly genus (Diptera: Syrphidae) on the Balkan Peninsula under future climate change. Biol. Conserv. 212:216-229.

Ricotta, C., A. Stanisci, G.C. Avena and C. Blasi. 2000. Quantifying the network connectivity of landscape mosaics: a graph-theoretical approach. Community Ecol. 1:89-94. 
Rotheray, G.E. and F. Gilbert. 2011. The Natural History of Hoverflies. Forrest Text, Ceredigion, Wales, UK.

Sarthou, J., A. Ouin, F. Arrignon, G. Barreau and B. Bouyjou. 2005. Landscape parameters explain the distribution and abundance of Episyrphus balteatus (Diptera: Syrphidae). Eur. J. Entomol. 102:539-545.

Schindler, S., H. von Wehrden, K. Poirazidis, T. Wrbka and V. Kati. 2012. Multiscale performance of landscape metrics as indicators of species richness of plants, insects and vertebrates. Ecol Indic. 31:41-48.

Senapathi, D., L.G. Carvalheiro, J.C. Biesmeijer, C-A. Dodson, R.L. Evans, M. McKerchar, R.D. Morton, E.D. Moss, S.P.M. Roberts, W.E. Kunin and S.G. Potts. 2015. The impact of over 80 years of land cover changes on bee and wasp pollinator communities in England. Proc. R. Soc B. 282:1-8.

Sommaggio, D. 1999. Syrphidae: can they be used as environmental bioindicators? Agric. Ecosyst. Environ. 74:343-356.

Sommaggio, D. and G. Burgio. 2014. The use of Syrphidae as functional bioindicator to compare vineyards with different managements. Bull. Insectology 67:147-156.

Speight, M.C.D. 2008. Database of Irish Syrphidae (Diptera). Irish Wildlife Manuals, No.36, NPWS, Dept of Environment, Heritage and Local Government, Dublin, Ireland. pp. 338.

Speight, M.C.D. and E, Castella. 2001. An approach to interpretation of lists of insects using digitised biological information about the species. J. Insect Conserv. 5:131-139.

Speight, M.C.D., E. Castella, and P. Obrdlik. 2000. Use of the Syrph the Net database 2000. Syrph the Net: The database of European Syrphidae. Syrph the Net publications, Dublin.

Steffan-Dewenter, I., U. Munzenberg, C. Burger, C. Thies and T. Tscharntke. 2002. Scale-dependent effects of landscape context on three pollinator guilds. Ecology 83:1421-1432.

Tscharntke, T., A.M. Klein, A. Kruess, I. Steffan-Dewenter and C. Thies. 2005. Landscape perspectives on agricultural intensifica- tion and biodiversity-ecosystem service management. Ecol. Lett. 8:857-874.

Vandewalle, M., F. De Bello, M.P. Berg, T. Bolger, S. Dolédec, F. Dubs, C.K. Feld, R. Harrington, P.A. Harrison, S. Lavorel, P. Martins Da Silva, M. Moretti, J. Niemelä, P. Santos, T. Attler, J.P. Sousa, M.T. Sykes, A.J. Vanbergen and B.A. Woodcock. 2010. Functional traits as indicators of biodiversity response to land use changes across ecosystems and organisms. Biodivers. Conserv. 19:2921-2947.

Velli, A., D. Sommaggio, B. Maccagnani and G. Burgio. 2010. Evaluation of environment quality of a protected area in Northern Italy using Syrph the Net method. Bull. Insectology 63:217-224.

Vujić, A., S. Radenković, T. Nikolić, D. Radišić, S. Trifunov, A. Andrić, Z. Markov,S. Jovičić, S. Mudri Stojnić, M. Janković, and P. Lugonja. 2016. Prime hoverfly (Insecta: Diptera: Syrphidae) areas (PHA) as a conservation tool in Serbia. Biol. Conserv. 198:22-32.

Walz, U. 2011. Landscape structure, landscape metrics and biodiversity. Living Rev. Landscape Res. 5:1-35.

With, K.A. 1997. The application of neutral landscape models in conservation biology. Conserv. Biol. 11:1069-1080.

Received October 9, 2017

Revised December 1, 2017 Accepted December 18, 2017

\section{Electronic Appendices}

Table A1. Landscape variables (EXCEL file).

Table A2. Observed species richness (Merodon and Cheilosia species richness and total species richness), and BDMF values during 2 periods (1990-2006 and 2006/2014) for ten study sites (1-10).

The Appendices may be downloaded from www.akademiai.com. 